\title{
Analysis of suspension bridge tunnel-type anchorage construction on the stability of surrounding rock
}

\author{
Nana $\mathrm{Li}^{1 *, 2}$, Yongqiang Zhou ${ }^{2}$, Yanqiang $\mathrm{Zhao}^{1}$ and Guiju $\mathrm{Li}^{1}$ \\ ${ }^{1}$ Wuhan Library, Chinese Academy of Sciences, Wuhan, Hubei, 430071, China \\ ${ }^{2}$ State Key Laboratory of Geomechanics and Geotechnical Engineering, Institute of Rock and Soil Mechanics, Chinese Academy of \\ Sciences, Wuhan, Hubei, 430071, China
}

\begin{abstract}
In order to study the interaction between the left and right tunnels of suspension bridge tunneltype anchorage, the finite difference numerical software is used to analyze the mechanical properties of the surrounding rock during the construction process. A numerical analysis model based on FLAC3D is established to analyze the stress, displacement and plastic zone changes of the surrounding rock of right tunnel anchor cavern during the construction of left tunnel anchor cavern. The right tunnel anchor cavern is excavated firstly, and then the left tunnel anchor cavern is excavated. The numerical simulation results show that the main displacement of the right tunnel occurs in the construction stage of the anchor plug body and the rear anchor cavern of the left tunnel. During the excavation of the left tunnel, the plastic zones of the left and right tunnel anchor caverns are only connected above the middle of the waist wall. Therefore, it is suggested that during the construction process, especially in the excavation stage of the anchor plug body and the rear anchor cavern, the area above the middle of the tunnel waist wall should be strengthened in time to ensure the construction safety.
\end{abstract}

\section{Introduction}

Tunnel anchor is a kind of anchorage in suspension bridge. Compared with gravity anchor, tunnel anchor can significantly reduce the cost and has less influence on the surrounding environment. (Lu, Y.C., 2003) Tunnel anchors combine the surrounding rock and the anchorage to bear the force as a whole, which is more reasonable in the structure and is widely used in areas with small joints and good mechanical properties of rock mass.

Because tunnel anchors have high requirements for the integrity and strength of surrounding rocks, there are few cases of tunnel anchors used in the existing suspension bridges all over the world. In 1932, tunnel-type anchorage was firstly used in the Washington Bridge (Ammann, O.H., 1933) . San Francisco-Oakland Bay Bridge in the United States was the second one using tunnel-type anchorage (Gorman, J.A. et al., 2015). Then the tunnel-type ancorage was used widely in the world. For example, the Forth Road Bridge in the United Kingdom(Larsen, K.R., 2013), Shimotsui-Seto bridge in Japan(Kadooka, M., 1988) and Guangdong Humen Bridge in China (Xia, C.C. et al., 1997) have adopted tunnel anchors. According to statistics, in the 20 th century, tunnel anchors were used in only 7 out of 39 suspension bridges built in the world, accounting for $17.9 \%$ of the total.(Zhu, Y. et al., 2005) At present, the research on tunnel anchors mainly adopts model tests and numerical simulations, including the ultimate bearing

\footnotetext{
* Corresponding author: linn@whlib.ac.cn
}

capacity, stability, interaction between surrounding rocks and tunnel anchors. (Xia, C.C. et al., 1997; Liao, C.H. et al., 2005; Zhu, Y. et al., 2005; Zhang, Q.H. et al., 2015; Yan, G.F. et al., 2019) For example, Xia et al. (Xia, C.C. et al., 1997) investigated the deformation properties and possible failure modes of tunnel-type anchorage. Zhu et al. (Zhu, Y. et al., 2005) studied the main construction and bearing process of tunnel-type anchorage by using the finite element method. The deformation properties of rock mass in different stages, such as, cavern excavation, plug body casting, were analyzed. Yan et al. investigated the reactions of anchorages and estimated the ultimate bearing capacity of tunnel-type (Yan, G.F. et al., 2019).

Compared with the model test, numerical simulation can consider multiple working conditions and is economical, so it is an ideal research method. This paper aims to investigate the mechanical characteristics of surrounding rock of the right tunnel anchor cavern during the excavation of left tunnel anchor cavern. Based on a large-span suspension bridge tunnel anchor project in southwest China, a numerical calculation model is established to study the surrounding rock stress distribution, deformation characteristics and plastic zone of surrounding rock during excavation. The results can provide useful reference for the construction of tunneltype anchorage.

\section{Project overview}


A single span steel truss suspension bridge with a main span of $1386 \mathrm{~m}$ in Southwest China has a design deck elevation of $1787 \mathrm{~m}$. The total length of the bridge is $1720 \mathrm{~m}$, and the bridge height is about $335 \mathrm{~m}$. Tunnel anchors are adopted on both sides of the bridge. The incident angle of the tunnel anchor center is $42^{\circ}$ and the length of tunnel anchor is about $70 \mathrm{~m}$ (the total length of anchorage is about $81 \mathrm{~m}$ ).

The anchor plug body is located in the hard, moderately weathered, dense, almond-shaped basalt rock body (a thin layer of moderately weathered tuff is sandwiched in the front anchor cavern). The main stressbearing parts (middle and lower parts) of the anchor plug body is in the relatively complete III surrounding rock in the unloading zone.

\section{Numerical simulation}

\subsection{Establishment of the numerical model}

Based on the comprehensive consideration of the geological structure and geotechnical characteristics of the area, the discrete element difference software FLAC3D was used for numerical simulation. The three-dimensional geomechanical model was shown in Fig.1. The constitutive relationship of each rock and soil layer adopts the elasticplastic model, and the yield criterion adopts the Mohr Coulomb strength criterion.

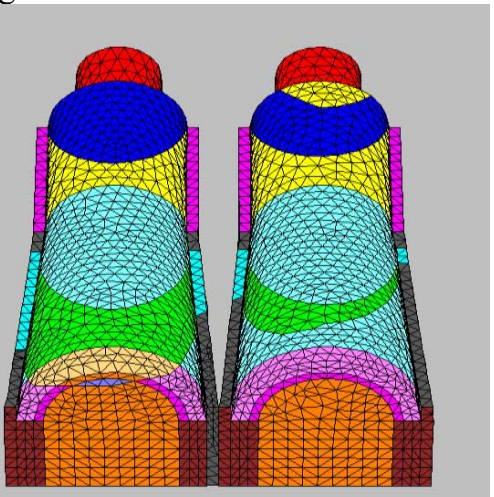

(a) Front view of the numerical model

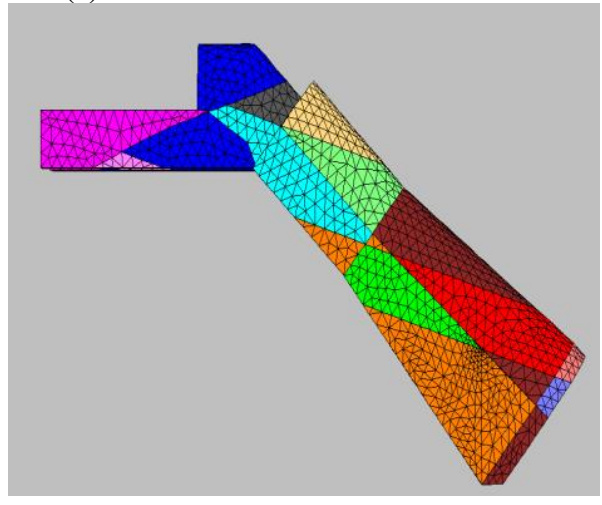

(b) Side view of the numerical model

Fig.1 Three-dimensional geomechanical model

The mechanical parameters of surrounding rock are shown in Table. 1. In this paper, the negative stress means the compressive stress, and the positive stress represents the tensile stress.
Table 1. Mechanical parameters of surrounding rock and

\begin{tabular}{|c|c|c|c|c|c|}
\hline Rock type & $\begin{array}{c}\text { Elastic } \\
\text { modulus } \\
\text { GPa }\end{array}$ & $\begin{array}{c}\text { Passion } \\
\text { s ratio }\end{array}$ & $\begin{array}{c}\text { Cohesio } \\
\mathrm{n}(\mathrm{MPa})\end{array}$ & $\begin{array}{c}\text { Internal } \\
\text { friction } \\
\left.\text { angle }{ }^{\circ}\right)\end{array}$ & $\begin{array}{c}\text { Tensile } \\
\text { trength(MP } \\
\text { a) }\end{array}$ \\
\hline $\begin{array}{c}\text { Strongly } \\
\text { weathered basalt }\end{array}$ & 0.50 & 0.28 & 0.35 & 30 & 0.30 \\
\hline $\begin{array}{c}\text { Moderately } \\
\text { weathered basalt } \\
\text { V }\end{array}$ & 2.00 & 0.27 & 0.50 & 38 & 0.45 \\
\hline $\begin{array}{c}\text { Moderately } \\
\text { weathered basalt } \\
\text { IV }\end{array}$ & 4.50 & 0.22 & 0.70 & 40 & 0.65 \\
\hline Tuff & 0.30 & 0.28 & 0.20 & 35 & 0.15 \\
\hline C25 concrete & 28.00 & 0.20 & 25.00 & 45 & 1.78 \\
\hline C30 concrete & 30.00 & 0.20 & 30.00 & 45 & 2.01 \\
\hline
\end{tabular}

According to the construction process of tunnel anchors, the right tunnel anchor was excavated first and then the left tunnel anchor was excavated. After the right anchor tunnel excavation is completed, the left tunnel anchor needs to be excavated. The excavation steps of the left tunnel anchor was as followed: Here the benching excavation method was adopted. Each step of the spacing is $5 \mathrm{~m}$. When the front anchor room is excavated, the excavation step took three steps, i.e. , the first step is $10 \mathrm{~m}$, the second step is $13.65 \mathrm{~m}$, the last step is to excavate the middle and lower steps, and then the anchor plug body was excavated. It is divided into five steps, the first 4 steps are $10 \mathrm{~m}$ each, the last step is to excavate the middle and lower steps. For the rear anchor cavern, the excavation was done by one step. Finally, the anchor plug body was filled and the second lining was applied. For each step, the deformation of each monitoring point (including the upper arch, waist wall and inverted arch), the corresponding plastic zone distribution and stress change for the right tunnel was monitored. The layout of the profile (such as $1-1,2-2,3-3,4-4$ and 5-5) and monitoring points (1\#, 2\#, $3 \#$ and 4\#) is shown in Fig. 2.

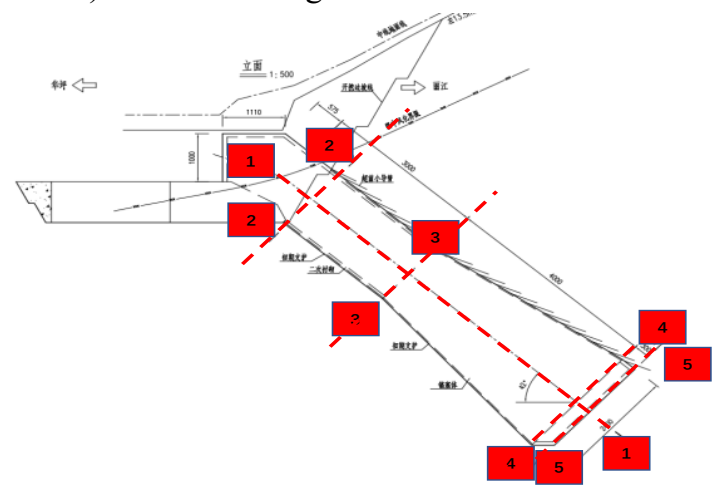

(a) Layout of monitoring section position 


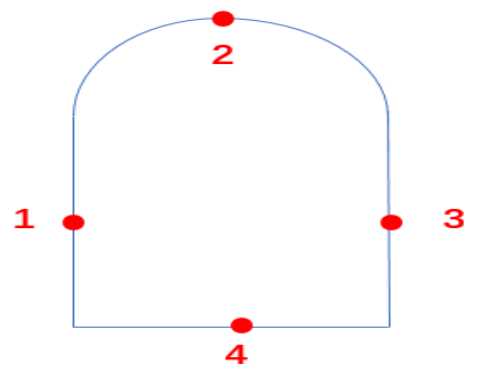

(b) Layout of monitoring points

Fig.2 Layout of each section position and monitoring points

\subsection{Stress analysis of surrounding rock}

During the excavation of the anchor cavern of the left tunnel, the stress variation at different sections of the anchor cavern of the right tunnel were analyzed. The excavation of the left tunnel anchor cavern has little effect on the maximum principal stress value at the 1-1 section and the 3-3 section of the right tunnel anchor cavern. The maximum principal stress value at the 1-1 section remains almost unchanged at $2.7 \mathrm{MPa}$. When the left tunnel anchor cavern is excavated to the 3-3 section, stress concentration will appear around the right tunnel cavern at the 3-3 section. When the tunnel face of the left tunnel anchor cavern is far away from 3-3, the maximum principal stress value remained basically stable and the increment is less than $0.77 \mathrm{MPa}$. During the first 6 steps of the excavation of the left tunnel anchor cavern, local tensile stress appeared at the rear end of the anchor plug body of the 11 section of the right tunnel. However, with the completion of the left tunnel anchor cavern, the maximum local tensile stress showed a decreasing trend as a whole, and the maximum tensile stress was $10.92 \mathrm{KPa}$.

\subsection{Displacement analysis of surrounding rock}
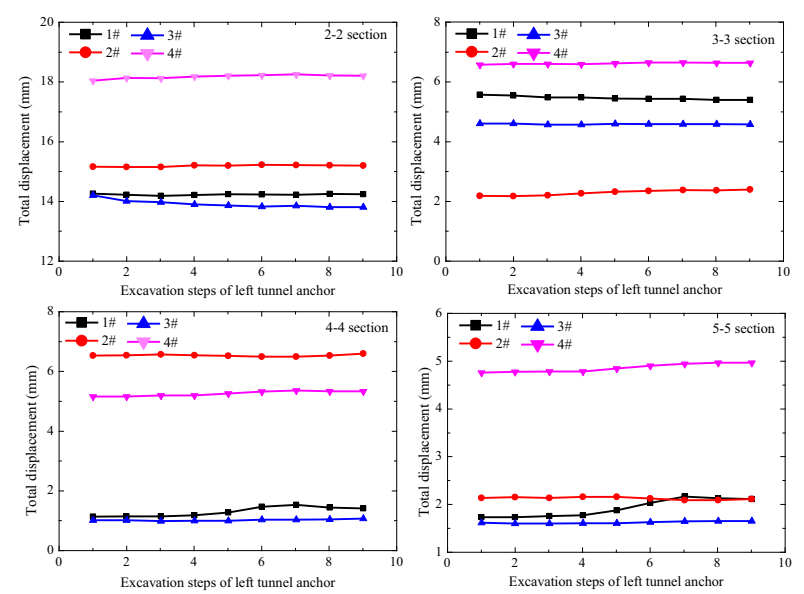

Fig.3 The total displacement curve of each monitoring point at different profile positions

During the excavation of the left tunnel anchor cavern, the displacement of the surrounding rock on 1-1 and 3-3 sections of the right tunnel anchor cavern were analyzed. The monitoring points of the 2-2 section, 3-3 section, 4-4 section and 5-5 section of the right tunnel anchor cavern is shown in Figs. 3-4.
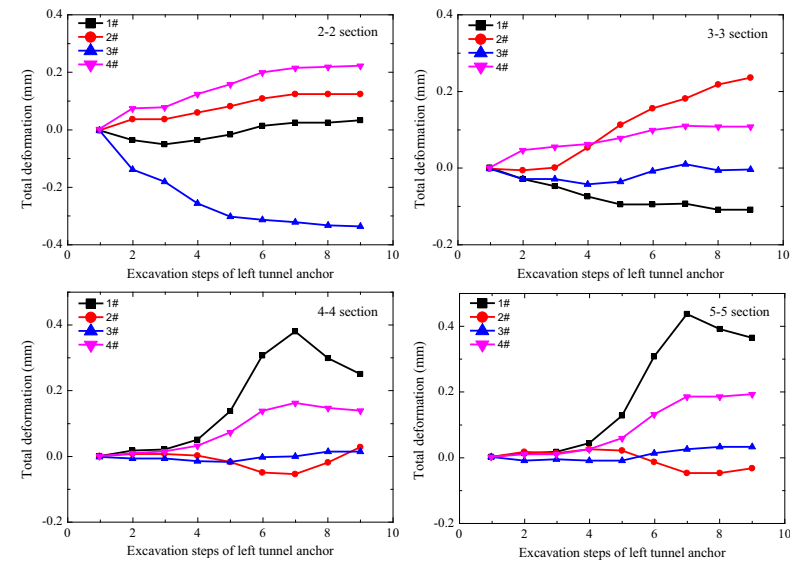

Fig.4 The total deformation curve of each monitoring point at different profile positions

It can be seen from Figs. 3-4 that the excavation of the left tunnel anchor cavern has little effect on the displacement of each monitoring point of the right tunnel anchor cavern, and at the same time it has different effects on the displacement value of different monitoring points at each section. The largest displacement change is the left waist wall at section 5-5 (monitoring point $1 \#$ ), the largest increment is about $0.43 \mathrm{~mm}$, followed by the right waist wall at section 2-2 (monitoring point $3 \#$ ), the largest increment is about $0.34 \mathrm{~mm}$, followed by the crown at section 3-3 (monitoring point 2\#), with a maximum increase of about $0.24 \mathrm{~mm}$, and finally the inverted arch at section 2-2 (monitoring point 4\#), with a maximum increase of being $0.22 \mathrm{~mm}$. When the left tunnel anchor cavern was excavated to the 9th step, the maximum displacement at section 2-2, 3-3 and 5-5 occurred at monitoring point $4 \#$, the upward rebound was about $18.25 \mathrm{~mm}, 6.66 \mathrm{~mm}$ and $4.96 \mathrm{~mm}$, respectively. For section 4-4, the maximum displacement occurred at monitoring point $3 \#$ and the upward rebound was $6.55 \mathrm{~mm}$ when the left tunnel anchor cavern was excavated to the 9 th step.

\subsection{Plastic zone analysis of surrounding rock}

During the excavation of the left tunnel anchor chamber, the change of shear strain increment at the position of 1-1 and 3-3 sections of the right tunnel anchor chamber were analyzed. It was found that the excavation of the left tunnel anchor cavern have little effect on the surrounding rock shear strain increment around the right tunnel anchor cavern at 1-1 and 3-3 sections. The maximum shear strain increment appeared at the inverted arch in front of the right tunnel anchor cavern for 1-1 and 3-3 sections, and the shear strain increment is 0.0176 and 0.0129 , respectively.

During the excavation of the left tunnel anchor cavern, the plastic zone distribution changes at 1-1, 3-3 and 4-4 sections of the right tunnel anchor cavern were analyzed. The excavation of left tunnel anchor cavern has little influence on the plastic zone distribution of the right tunnel anchor cavern at 1-1, 3-3 and 4-4 sections. However during the excavation of the left tunnel anchor cavern, the tuff interlayer above the tunnel anchor cavern is locally damaged due to the weak lithology. From the plastic zone distribution of 1-1 section, it can be seen that a certain volume of plastic zone appears at the surrounding rock 
above the upper arch and above the middle part of the waist wall. When the left tunnel anchor cavern was excavated, the plastic zone above the middle part of the tunnel passes through, and a small amount of plastic zone was distributed at the inverted arch of the left cavern.

The total volume change of the plastic zone is shown in Fig.5. The total volume of the plastic zone increases with the excavation of the left tunnel anchor cavern, and the total volume of the plastic zone will increase sharply after the excavation to step 5, increasing from $137434.19 \mathrm{~m}^{3}$ to $146192.61 \mathrm{~m}^{3}$.

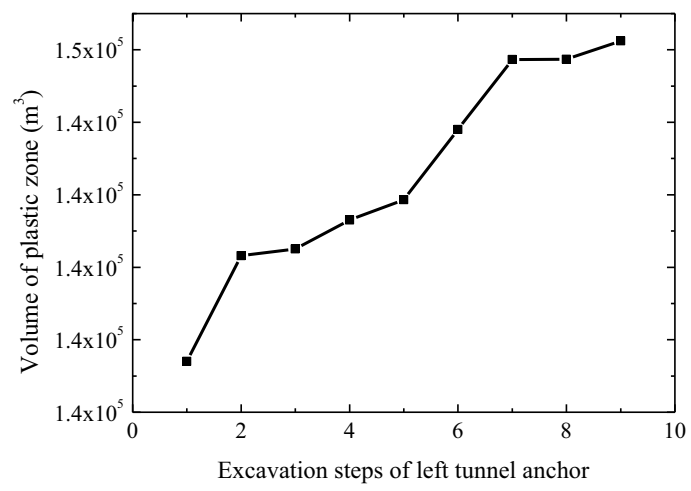

Fig.5 Total volume curve of the plastic zone

\section{Conclusion}

In this paper, the geological generalization model of the tunnel anchor is established by using the threedimensional finite element software FLAC3D. Through numerical simulation, the following conclusions are drawn. During the construction process of the followed tunnel anchor cavern, the maximum increase of the displacement of the first tunnel is about $0.43 \mathrm{~mm}$, and the main displacement occurs in the construction stage of the anchor plug body and the rear tunnel anchor cavern. The influence of tunnel excavation on the surrounding rock plastic zone is not very great, and the left and right tunnel anchor caverns are only connected above the middle of the waist wall. In the excavation stage of the followed anchor cavern, the support of the area above the middle part of the tunnel waist wall should be strengthened in time, and the surrounding rock above the middle part of the waist wall and the upper arch, especially the tuff interlayer, should be monitored to ensure the integrity of the surrounding rock.

\section{Acknowledgments}

This paper was supported by Open Research Fund of State Key Laboratory of Geomechanics and Geotechnical Engineering, Institute of Rock and Soil Mechanics, Chinese Academy of Sciences, Grant NO. Z017023.

\section{References}

1. Lu, Y.C. (2003) The east tunnel - anchor of Chongqing Egongyan Yangtze River Bridge[J]. China City Engineering, (6): 31-34. (in Chinese)
2. Ammann, O.H. (1933) George Washington Bridge general conception and development of design. Trans. ASC 9 (1): 56-62.

3. Gorman, J.A., Gross, D., Hall, T.S., Matty, S., Christoffersen, S., Cavendish-Tribe, A., Shulock, R. (2015) San Francisco-Oakland Bay Bridge anchor rod cracking issues. Mater. Perf., 54 (6): 52-57.

4. Larsen, K.R. (2013) Dehumidification slows corrosion of Forth Road Bridge cables. Mater. Perf., 52 (4): 22-24.

5. Kadooka, M., Okada, M., Hashida, Y., Kuwamoto, S. (1988) Cable erection of ShimotsuiSeto bridge. KOBELCO Technol. Rev., 4: 11-14.

6. Xia, C.C., Cheng, H.X., Li, R.Q. (1997) Testing study on field structure model of the east anchorage of Guangdong Humen Bridge. Chinese Journal of Rock Mechanics and Engineering, 16 (6): 571-576. (in Chinese)

7. Zhu, Y., Wei, J., Li, H., et al. (2005) Analysis of displacement of tunnel-type anchorage for a largespan suspension bridge. Chinese Journal of Rock Mechanics and Engineering, 24(19): 3588-3588. (in Chinese)

8. Liao, C.H., Peng, Y.C., Yang, Y.Q. (2005) Design and structural capacity assessment of tunnel-type anchorage for long-span suspension bridge. Bridge Construction, 02: 47-49+76. (in Chinese)

9. Zhu, Y., Wei, J., Li, H., Yang, M.J. (2005) Analysis of displacements of tunnel-type anchorage for a large-span suspension bridge. Chinese Journal of Rock Mechanics and Engineering, 24 (19): 3588 3593. (in Chinese)

10. Zhang, Q.H., Yu, W.M., Yu, Z.F., et al. (2015) Field model tests on pullout capacity of tunnel-type anchorages of PULI bridge. Chinese Journal of Rock Mechanics and Engineering, 34(1): 93-103. (in Chinese)

11. Yan, G.F., Wang, M.N., Li, R.F., et al. (2019) Research on mechanical reaction and ultimate capacity of tunnel-type anchorage of Daduhe Super Bridge. Chinese Journal of Underground Space and Engineering, 15(4): 1149-1155. (in Chinese) 